\title{
Adapting Orthopaedic Surgery Training Programs During the COVID-19 Pandemic and Future Directions
}

\author{
Andrew S Zhang, M.D., Mitchell Myers, M.D., Clarence J. Kee, M.D., \\ Kaylan N. McClary, M.D., R. Shane Barton, M.D., and Patrick A. Massey, M.D.
}

\begin{abstract}
The COVID-19 pandemic swept across the world, altering the structure and existence of graduate medical education programs across all disciplines. Orthopaedic residency programs can adapt during these unprecedented times to continue providing meaningful education to trainees and to continue providing high-quality patient care, all while keeping both residents and patients safe from disease. The purpose of this review was to evaluate the literature and describe evidence-based changes that can be made in an orthopaedic residency program to ensure patient and resident safety while sustaining the principles of graduate medical education during the COVID-19 pandemic. We describe measures that can be enacted now or during future pandemics, including workforce and occupational modifications, personal protective equipment, telemedicine, online didactic education, resident wellness, return to elective surgery, and factors affecting medical students and fellows. After a review of these strategies, programs can make changes for sustainable improvements and adapt to be ready for second-wave events or future pandemics. Level of Evidence: Level V.
\end{abstract}

$\mathbf{T}$ he novel coronavirus COVID-19 has unequivocally affected every facet of medicine. Issues such as management of limited resources and personnel, continued care in light of social and physical distancing and fear of acquiring from or transmitting the virus to loved ones are all strains salient even to the public eye. Graduate medical education is faced with an unprecedented challenge, without well-documented accounts of how to adjust while our health care system is in constant flux. Orthopaedic residencies, in particular, have been affected by mandated changes in surgical scheduling, reduced patient encounters and disturbances in education because of social-distancing

From the Department of Orthopaedic Surgery, Louisiana State University, Shreveport, Louisiana, U.S.A.

The authors report no conflicts of interest in the authorship and publication of this article. Full ICMJE author disclosure forms are available for this article online, as supplementary material.

Received June 17, 2020; accepted June 18, 2020.

Address correspondence to Patrick A. Massey, M.D., Department of Orthopaedic Surgery, Louisiana State University, 1501 Kings Highway, Shreveport, LA 71103,U.S.A.E-mail: pmasse@lsuhsc.edu

(C) 2020 THE AUTHORS. Published by Elsevier Inc. on behalf of the Arthroscopy Association of North America. This is an open access article under the CC BY-NC-ND license (http://creativecommons.org/licenses/by-nc-nd/4.0/). 2666-061X/201067

https://doi.org/10.1016/j.asmr.2020.06.008 guidelines. However, residencies are still expected to function and be effective in delivering high-quality care despite these conditions and the constant threat of nosocomial transmission.

During this pandemic, the American College of Graduate Medical Education (ACGME) has released guidelines for residency programs. It describes 3 stages: Stage 1 , business as usual; Stage 2, increased but manageable clinical demand; Stage 3, crossing a threshold beyond which the increase in volume and/or severity of illness creates an extraordinary circumstance where routine care education and delivery must be reconfigured to focus only on patient care." ${ }^{1}$ During Stage 2, ACGME recommends didactics be done via remote conferencing or be web based, and residents can be reassigned. Stage 3 occurs when the designated institutional official declares Pandemic Emergency Status. This provides a 30-day period when most common program requirements are suspended.

The purpose of this review is to evaluate the literature and describe evidence-based changes that can be enacted within an orthopaedic residency program to ensure patient and resident safety, sustaining the principles of graduate medical education during the COVID-19 pandemic and establish training protocols to withstand a future second wave. We describe workforce and occupational modifications, personal protective equipment 
(PPE), telemedicine, online didactic education, resident wellness, return to elective surgery, and factors affecting medical students and fellows.

\section{Background and Epidemiology}

The coronavirus was first described in humans in 1965 by Tyrrell and Bynoe while studying the secretions of an adult with common cold symptoms. ${ }^{2}$ Electron microscopy was performed by Almeida and Tyrrell on isolates from fluids obtained from organ cultures, and they described the "halo-like" appearance of the surface protein projections on the viral particles. ${ }^{3}$ This led to the coronavirus designation, derived from the Latin corona for "crown" or "halo." Other members of the coronavirus family have since been identified as causes of serious respiratory system infections in humans. These include both the SARS-CoV (severe acute respiratory syndrome coronavirus) in 2003 and the MERS-CoV (Middle Eastern respiratory syndrome coronavirus) in 2012. ${ }^{4,5}$ Epidemiologic studies after the SARS outbreak identified bats and palm civets as hosts of the virus in nature. ${ }^{6}$

On March 11, 2020, the World Health Organization declared COVID-19 a pandemic. ${ }^{7}$ By April 9, 2020, there were 1.5 million cases worldwide, with 89,000 deaths reported. ${ }^{8}$ This global crisis demanded an immediate change in residency-training programs and systematic improvements to counteract future threats.

\section{Physical Distancing: Restructuring Work Force and Occupational Modifications}

At a time when the coronavirus appears to be spreading at a seemingly exponential rate, governments heavily advocated for social distancing and even enacted stay-at-home orders. This entailed limiting interpersonal interaction to greater than 6 feet, elimination of group outings and gatherings, cancellation of classes and schools, and imposing travel restrictions. ${ }^{9,10}$ Because of the gravity of the social distancing, residencies can take several measures in order to comply with these recommendations and to maintain the overall health of the residents.

\section{Restructuring Workforce}

At the onset of the COVID-19 outbreak, individuals who were exposed or suspected of being exposed to infected patients were asked to quarantine for 2 weeks per recommendations by the Centers for Disease Control and Prevention (CDC). ${ }^{9,11}$ Many programs instituted weekly or bimonthly rotating schedules to mitigate risk to the orthopaedic team. Some programs used 1 team for inpatient care and another team for telemedicine, with rotations occurring every 2 weeks. ${ }^{12}$ Other trauma institutions have segmented into a 3-team system, with a trauma team rotation for 1 week followed by 2 weeks away from the hospital. ${ }^{13}$ Whether orthopaedic programs instituted a 2-team or 3-team approach, most rotation schedules centered on the idea of decreasing inpatient exposure risk and 14 days of minimal contact after an inpatient rotation. Our institution heeded these advisories and restructured our resident complement to incorporate them. ${ }^{14}$ With a total of 15 residents, 3 teams of 5 were established (Fig 1). The establishment of 3 individualized teams physically isolates residents from each other, thereby limiting any possible spread of the virus among coresidents and decreasing the likelihood of an entire residency's being infected simultaneously. These groups of residents rotated weekly in an inpatient, outpatient and elective/off-site setting.

\section{Inpatient Care Team}

The inpatient setting was expected to contain a higher concentration of patients with COVID-19 and, therefore, placed the residents at highest risk of being exposed to the virus. In Wuhan, China, $79.2 \%$ of orthopaedic surgeons who contracted COVID-19 believed it came from the inpatient wards. ${ }^{15}$ This inpatient group of our residents was the main team tending to all operative activities during this time when surgical volumes have dampened, and all elective cases have remained postponed. This team did rounds and rendered care for the orthopaedic inpatients as well as fielding consults within the hospital and through the emergency department. All other residents were asked to stay away from the inpatient premises while they were off that rotation. This, in essence, theoretically spared the remaining residents from being exposed to a high viral burden and from the heightened risk of nosocomial transmission. The inpatient team would then rotate out of the hospital for the next 2 weeks. The rotating nature of this team-based approach inherently provided a built-in self-quarantine time of 2 weeks, until they were needed back in the inpatient setting. With fewer demands in the outpatient and elective settings, there was adequate substitution by members of the team, should any individual fall ill and need to be replaced.

\section{Outpatient Care Team}

In the outpatient setting, clinical encounters were pared to only essential visits. This entailed postponing new nonurgent consults and rescheduling follow-ups for chronic ailments. Residents still engaged in seeing these outpatients, either by telemedicine or in person with ample PPE. Notably, the duties of this group of residents were limited to the outpatient setting and did not overlap with the residents at the other sites.

\section{Elective/Off-Site Rotations}

The elective/off-site rotations were clustered in 1 group because they had become less demanding while state governments maintained their elective restrictions. Residents used this week to rest and recuperate if they 
Fig 1. Schematic of residents' allocations and rotations during the pandemic. Rotating schedule that changes every 7 days. For a 15-resident complement, there are 5 residents on the inpatient service, 5 residents on the outpatient-care service and 5 residents on the elective/off-site service. This limits inpatient exposure of residents and limits contact between resident teams. *VA, Veterans Affairs Hospital.
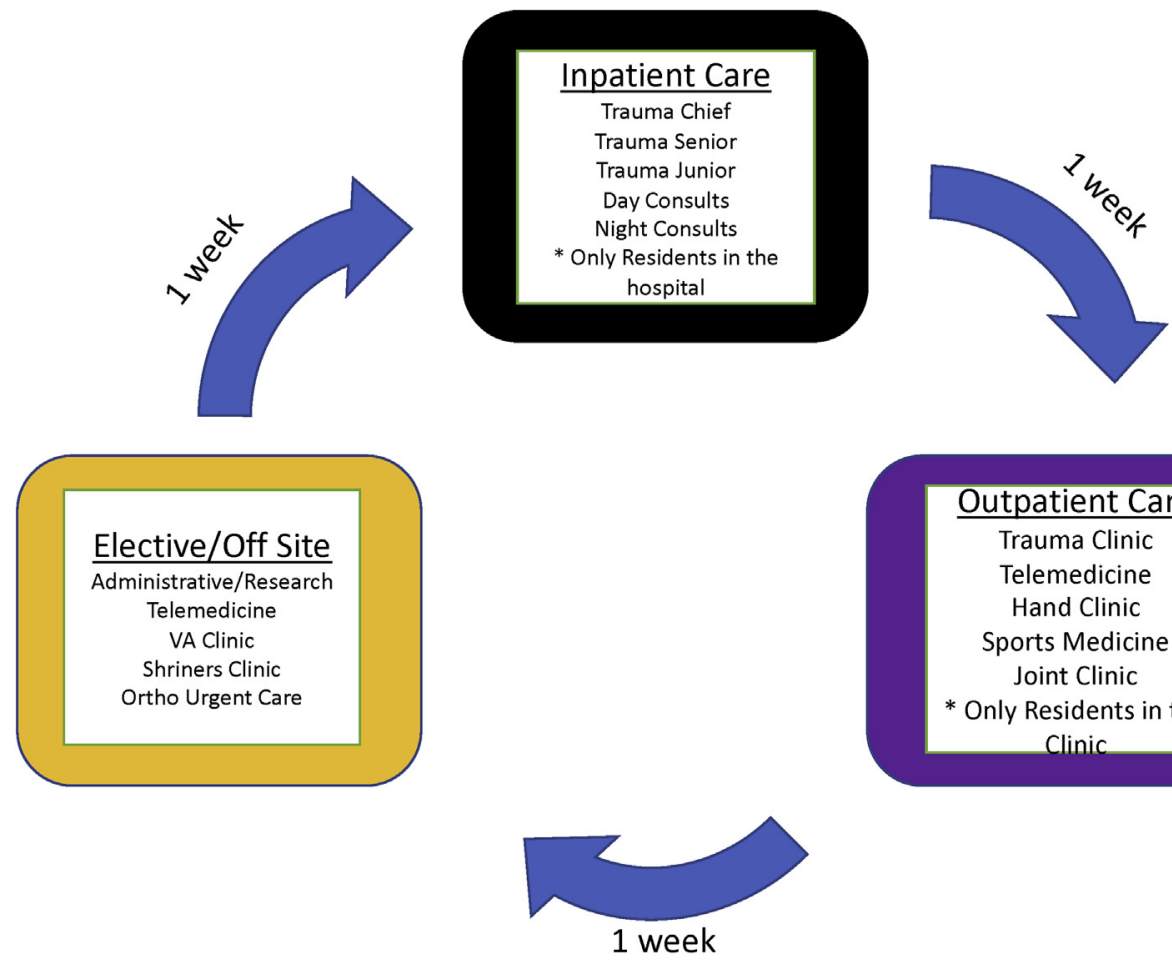

became ill. If they were absolved of clinical responsibilities, residents were encouraged to make progress in research and scholarly activity and to participate in educational activities, such as reading and answering questions. Senior residents used this dedicated week to perform intensive studying in preparation for board examinations because they would otherwise be sent to Board Review Courses during this time.

\section{Monitoring Exposure Risk and Return to Normal Operations}

Although each residency is innately different in its number of constituents and in the nuances of rotations and sites, programs can draw from these principles and restructure their teams accordingly. Based on the risk of inpatient exposure, we recommend any rotations schedule involve weekly changes, with a dedicated inpatient team that rotates out. Most programs that have adjusted have incorporated some variation of this principle. ${ }^{16,17}$ All residents receive SARS-CoV-2 reverse transcription polymerase chain reaction testing every 2 weeks. When residents tested positive, they would selfquarantine for 2 weeks and provide telemedicine services from home, and there was no known spread to any other residents or faculty. The state legislature has lifted the stay-at-home order, so we have returned to a traditional rotation schedule. The benefit of the 3-team model is that it provides comprehensive coverage of all services and can be quickly implemented. In the event that there is a second-wave phenomenon, programs can easily convert to the 3 -team rotation so as to mitigate inpatient risk to residents.

\section{Occupational Modifications}

Residents working in the hospital setting are intrinsically predisposed to nosocomial acquisition of COVID- 19 . This, in turn, translates not only to their becoming ill themselves but also to perpetuating the illness to their families at home, their colleagues and their patients. Certain precautions can be taken during this time to prevent inadvertent propagation of this virus.

\section{Individual Workstations}

Aside from isolating residents into separate groups, another measure for those residents working together on the same team is establishing individual workstations. Coronavirus has been found to persist on inanimate objects for times ranging from several hours to several days. ${ }^{18}$ Communal tools, such as computers, keyboards and office supplies, can act as niduses for infection if they are not properly cleansed before used by another resident. At our institution, individualized workstations for each resident were created, separating desks and computers for residents to use at least 6 feet apart from each other and with physical barriers between each (Fig 2). If a team member should become unknowingly infected, he or she can potentially spread the virus to the rest of the residency by using the communal computers and keyboards. However, by establishing these individualized workstations, sharing 


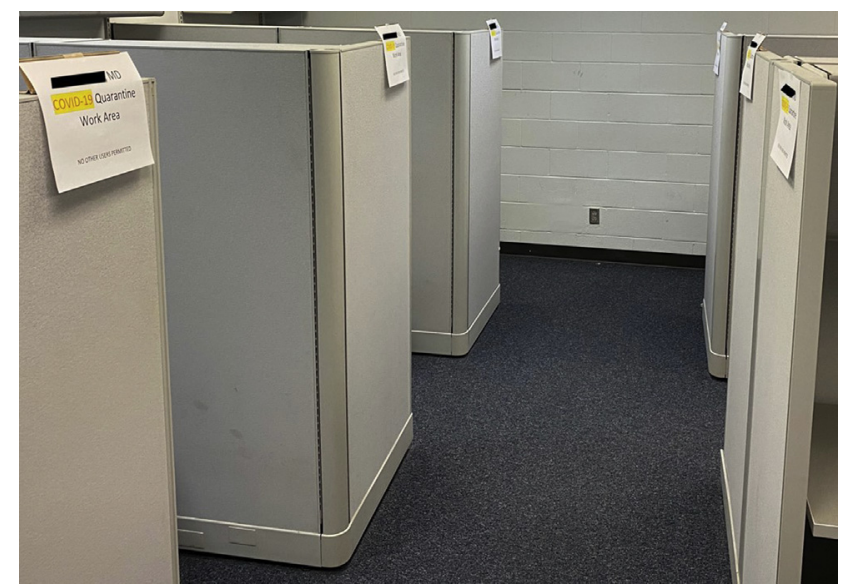

Fig 2. Optimizing personal protective equipment (PPE) for health care providers. Individualized workstations can be created to promote physical/social distancing and eliminate the sharing of communal items, which may act as fomites.

of these communal items can be reduced, which reduces cross-contamination.

The use of PPE has been emphasized in efforts to mitigate the spread of the coronavirus. Various institutions have been releasing guidelines centered on the CDC recommendations for these times, including:

- The National Institute for Occupational Safety and Health-approved N95 respirators

- Gowns

- Gloves

- Face shields/eye protection.

The full list of N95 National Institute for Occupational Safety and Health-approved masks can be found on the CDC website: (https://www.cdc.gov/niosh/npptl/ topics/respirators/disp_part/n95listl.html).

\section{Preserving PPE Resources}

The American College of Surgeons committee released trauma recommendations for COVID-19, suggesting the preservation of PPE by limiting contact for nonessential personnel, clustering work needed to be done with a single patient (both to limit exposure and to reduce PPE use) and reuse of PPE when appropriate. ${ }^{19}$

\section{Proper Use of PPE}

It is important that health care workers review how to use PPE properly. The CDC created training models covering the various PPE combinations, including instructions on how to safely don and doff them during the Ebola virus emergence. These training modules can be found at https://www.cdc.gov/vhf/ebola/hcp/ppetraining/index.html.

\section{Telemedicine}

The Centers for Medicare and Medicaid have stated that telehealth, telemedicine and related terms generally refer to the exchange of medical information from 1 site to another through electronic communication so as to improve patients' health. This exchange of medical information spans basic telephone services to laptops and tablets. Electronic health records have been integrating and streamlining telemedicine capabilities into their technologies, while stand-alone videoconferencing apps such as Zoom have transitioned into health care with Zoom for Healthcare. Some applications such as Amwell are also seamlessly integrated with popular electronic health records such as EPIC and Cerner, which have already been adopted by many major hospital systems.

\section{Expansion of Telemedicine}

The CDC and the World Health Organization urged hospitals to expand their telemedicine services by late February 2020. The expansion of the Telehealth 1135 waiver then went into effect on March 6, 2020. According to the Centers for Medicare and Medicaid, this new waiver allows "Medicare to pay for office, hospital, and other visits furnished via telehealth across the country and including in patients' places of residence." ${ }^{20}$ Before this waiver, payment for telehealth by Medicare was on a "limited basis." The waiver also allowed patients without established relationships with the practitioners to be seen without audit during this public health emergency. ${ }^{20}$ Additionally, the U.S. Department of Health and Human Services Office of Civil Rights has relaxed the Health Insurance Portability and Accountability Act-compliance regulations, giving rise to the use of popular platforms, such as FaceTime, Facebook Messenger and Skype, for telemedicine visits without fear of compliance penalties (Table 1).

\section{Implementation of Telemedicine}

In our experience, converting many nonurgent appointments to telemedicine visits was accomplished with relative ease. Previously, the Epic software was updated to allow the telemedicine feature on Haiku and the Canto feature found on portable devices. A patient must be signed up for MyChart and download the MyChart app onto their iOS or Android device. The time for MyChart enrollment and troubleshooting technical difficulties is the rate-limiting step for implementation of this technology. Once the enrollment has been completed, changing patients to a MyChart Video Visit through Epic and completing the visit is straightforward. Incorporating a group of clinical assistants and technical support to screen the patients before the visit allows for more efficient workflows and more pleasant experiences for the patients.

\section{Incorporating Telemedicine}

Once an acceptable system has been established to convert nonurgent visits to telemedicine visits, 
attention can then be directed toward the user interface and improving efficiency. The Canto iPad app is a more robust tool for telemedicine; it adds features such as notifications of patient status, an improved microphone system and a larger screen for viewing. Requesting hospital administration to purchase or applying for governmental assistance for improved technology to deliver quality care is a helpful step in the success of telemedicine.

The American Academy of Orthopaedic Surgeons has provided a resource guide that aids in billing and Health Insurance Portability and Accountability Act compliance and links to resources: https://Www.aaos.org/ globalassets/about/COVID-19/aaos-telemedicine-resource -guide.pdf. ${ }^{21}$ Please review these guidelines before engaging in any telemedicine visits to ensure correct billing and coverage of services offered.

\section{Hybrid In-person and Telemedicine Clinics}

As we have returned to seeing patients in person at our clinics, we have limited patients' visits to $15 \mathrm{mi}$ nutes apart so as to respect physical distancing. As fewer patients could be seen physically, we incorporated telemedicine concurrently during these clinics. For example, we would have an in-person visit every 15 minutes during an 8-hour clinic and also have online visits every 15 minutes, alternating with the inperson visits. This allowed our clinics to respect physical distancing while still finishing at a reasonable time.

\section{Future of Telemedicine in Orthopaedic Surgery}

Based on our overwhelmingly successful experience with telemedicine during the height of COVID-19, the future of its continued use is significant in our department. We have found this approach especially helpful for underserved patients who have difficulty traveling several hours to see us, and there has been no compromise in the high quality of care. Online visits will be incorporated more routinely, especially for patients who are in nursing homes or live far away. Additionally, now that the telemedicine system has been integrated into all of our clinics, we are ready to transition back to all-telemedicine clinic encounters if a second wave resurgence of COVID-19 occurs.

\section{Approach to Didactic Education: Virtual Learning and Meetings}

In the wake of the global spread of COVID-19, sweeping measures were taken by institutions of higher learning throughout the country to curtail large cohorts for educational purposes. These efforts were made to promote physical distancing and prevent further spread of the virus. Similarly, didactics are fundamental to an orthopaedic resident's graduate medical education. Although these were traditionally live lectures, residencies also have turned to other online mediums in order to respect distancing guidelines. ${ }^{12,17,22}$ In our experience, an important feature of education is the ability to screen-share, so that an individual can share prepared presentations with everyone logged into the meeting. Table 2 outlines several popular alternative platforms that other institutions have already adopted. (The authors disclose no proprietary or monetary investment in these listed products.)

Instead of physically gathering residents, these conferences can be streamed during mutually amenable times and dates. Orthopaedic residencies can hold these didactics at the times regularly scheduled before the pandemic or establish other times. In promoting these activities, residents were provided some semblance of normalcy because they were still able to virtually interact with one another and still maintain the structure of orthopaedic education with the backdrop of an unpredictable health crisis. Future directions include having the ability for staff to be present remotely for residents' lectures. Additionally, guest speakers were easily able to present to our residents from remote locations. If there is a resurgence of COVID-19 cases, the ease of use of these applications allows them to be used to convert conferences rapidly to remote versus inperson meetings.

\section{Reallocation of Roles}

As resources are depleted in the hotspots of active coronavirus, the pool of health care personnel who would otherwise be at the frontlines of care, such as those in the intensive care unit and the emergency department, are also being exhausted as they, too, are falling ill with the virus. Orthopaedic residents and faculty were asked to be redeployed to staff these settings. ${ }^{23}$ In many instances, providers such as orthopaedic surgeons may not have had any formal training or significant experience in critical care during their training and must be reacquainted with, or in some instances learn, a dedicated skill set previously foreign to them. Certain programs are having their residents attend intensive training camps to prepare them for ICU-level duties. ${ }^{24,25}$ In these situations, residents are coordinated with intensive care nurses who host daylong workshops that expedite the training needed for these redeployed providers. Fortunately, there are also several supplements that can be accessed online to help in familiarization with these new skills. There are various online resources for the non-ICU clinician. The Society of Critical Care Medicine has created an online platform for training the non-ICU clinician for critical care, airway management and prone ventilation at https://covid19.sccm.org/nonicu.htm. The American College of Physicians also has a helpful website with multiple videos for critical care education at https:// www.acponline.org/featured-products/critical-care-videoshorts/view-critical-care-video-shorts. 


\begin{tabular}{|c|c|c|c|c|c|c|}
\hline Platform & Cost for Providers & $\begin{array}{l}\text { HIPAA- } \\
\text { Compliant }\end{array}$ & Compatibility & Mobile-Friendly & Unique Features & Website \\
\hline$\overline{\text { Amwell }}$ & $\begin{array}{l}\text { Integrated with EHR } \\
\text { pricing, but contact } \\
\text { company for more } \\
\text { details }\end{array}$ & Yes & $\begin{array}{l}\text { Apple iOS App } \\
\text { Google Android App } \\
\text { Google Chrome } \\
\text { Internet Explorer } \\
\text { Mozilla Firefox } \\
\text { Safari }\end{array}$ & Yes & $\begin{array}{l}\text { Some ancillary medical } \\
\text { equipment can be } \\
\text { purchased to } \\
\text { supplement encounters } \\
\text { Easily integrated with } \\
\text { several EHR systems }\end{array}$ & $\begin{array}{l}\text { https://business.amwell. } \\
\mathrm{com} /\end{array}$ \\
\hline Doxy.me & $\begin{array}{l}\text { Free, with options to } \\
\text { upgrade }\end{array}$ & Yes & $\begin{array}{l}\text { Google Chrome } \\
\text { Mozilla Firefox } \\
\text { Microsoft Edge } \\
\text { Safari 11+ } \\
\text { Safari iOS } \\
\text { Google Chrome on } \\
\text { Android }\end{array}$ & Yes & $\begin{array}{l}\text { Does not require download } \\
\text { of separate app; can } \\
\text { access via most popular } \\
\text { browsers } \\
\text { Appointment reminders } \\
\text { Self-scheduling }\end{array}$ & https://doxy.me/ \\
\hline $\begin{array}{l}\text { Facebook Messenger } \\
\text { Video Chat }\end{array}$ & Free & No & $\begin{array}{l}\text { Google Chrome } \\
\text { Microsoft Edge } \\
\text { Opera } \\
\text { iOS } 9+\end{array}$ & Yes & $\begin{array}{l}\text { Immediate familiarity; } \\
\text { widely used by patients } \\
\text { and providers } \\
\text { Easy to use } \\
\text { Compatible with most } \\
\text { devices }\end{array}$ & $\begin{array}{l}\text { https://www.facebook. } \\
\text { com/ }\end{array}$ \\
\hline FaceTime & Free & No & $\begin{array}{l}\text { Mac OS X 10.9.2+ } \\
\quad \text { iOS } 7+\end{array}$ & Yes & $\begin{array}{l}\text { Immediate familiarity; } \\
\text { widely used by patients } \\
\text { and providers } \\
\text { Easy to use } \\
\text { Limited to Apple devices }\end{array}$ & $\begin{array}{l}\text { https://support.apple.com/ } \\
\text { en-us/HT204380 }\end{array}$ \\
\hline Mend & $\begin{array}{l}\text { Single provider: Mend } \\
\text { Now } \$ 49 / \text { mo } \\
\text { Group: Mend Pro } \\
\text { Custom proposal }\end{array}$ & Yes & $\begin{array}{l}\text { Google Chrome } \\
\text { Microsoft Edge } \\
\text { Mozilla Firefox } \\
\text { Safari } \\
\text { iOS } 12.2+ \\
\text { Android 5.0+ }\end{array}$ & Yes & $\begin{array}{l}\text { Digital intake } \\
\text { Self-scheduling } \\
\text { Appointment reminders } \\
\text { Virtual chart } \\
\text { No software required }\end{array}$ & $\begin{array}{l}\text { https://www.mendfamily. } \\
\text { com/telemedicine- } \\
\text { benefits/ }\end{array}$ \\
\hline Skype & Free & No & $\begin{array}{l}\text { Google Chrome } \\
\text { Microsoft Edge } \\
\text { Windows } 10 \\
\text { Mac OS X 10.10+ } \\
\text { iOS 10+ } \\
\text { Linux } \\
\text { Android OS 4.0.4+ }\end{array}$ & Yes & $\begin{array}{l}\text { Largely familiar to patients } \\
\text { and providers }\end{array}$ & $\begin{array}{l}\text { https://www.skype.com/ } \\
\text { en/ }\end{array}$ \\
\hline $\begin{array}{l}\text { Skype for Business via } \\
\text { Microsoft Teams }\end{array}$ & $\$ 12.50-\$ 15 /$ user $/ \mathrm{mo}$ & Yes & $\begin{array}{l}\text { Windows } 10 \\
\text { Windows } 8.1 \\
\text { Mac OS X 10.11+ } \\
\text { iOS } 12+ \\
\text { Android } 8.0+\end{array}$ & Yes & $\begin{array}{l}\text { HIPAA-compliant version } \\
\text { of Skype }\end{array}$ & $\begin{array}{l}\text { https://www.skype.com/ } \\
\text { en/business/ }\end{array}$ \\
\hline
\end{tabular}




\begin{tabular}{|c|c|c|c|c|c|c|}
\hline Platform & Cost for Providers & $\begin{array}{l}\text { HIPAA- } \\
\text { Compliant }\end{array}$ & Compatibility & Mobile-Friendly & Unique Features & Website \\
\hline Spruce Care Messenger & $\begin{array}{l}\text { Basic: \$24/user/ month } \\
\text { Communicator: \$49/ } \\
\text { user/month }\end{array}$ & Yes & $\begin{array}{l}\text { Apple iOS app } \\
\text { Android app } \\
\text { Google Chrome } \\
\text { Mozilla Firefox } \\
\text { Mac Safari } \\
\text { Microsoft Edge }\end{array}$ & Yes & $\begin{array}{l}\text { Secure messaging available } \\
\text { Ability to share files }\end{array}$ & $\begin{array}{l}\text { https://www.sprucehealth. } \\
\text { com/ }\end{array}$ \\
\hline Updox & $\begin{array}{l}\text { Plans beginning at } \$ 80 / \\
\text { provider }\end{array}$ & Yes & $\begin{array}{l}\text { Google Chrome } \\
\text { Mozilla Firefox } \\
\text { Microsoft Edge } \\
\text { Safari 1l+ } \\
\text { Safari iOS } \\
\text { Google Chrome on } \\
\text { Android } \\
\text { Samsung Internet } \\
\text { Browser }\end{array}$ & Yes & $\begin{array}{l}\text { Entirely web-based } \\
\text { without app } \\
\text { Can integrate with EHR } \\
\text { Available secure texting } \\
\text { with patients } \\
\text { Yes, appointment } \\
\text { reminders }\end{array}$ & https://www.updox.com/ \\
\hline VSee & $\begin{array}{l}\text { Messenger: Free, with } \\
\text { options to upgrade } \\
\text { Clinic: } \$ 49 / \text { month per } \\
\text { provider, with options to } \\
\text { upgrade }\end{array}$ & Yes & $\begin{array}{l}\text { Windows } 7+ \\
\text { Mac OX X } 10.11+ \\
\text { Apple iOS } 11+ \\
\text { Android 5.0+ } \\
\text { Amazon Fire } 2014 \text { or } \\
\text { later }\end{array}$ & Yes & $\begin{array}{l}\text { Can screen share with } \\
\text { patients and annotate } \\
\text { Text capability available } \\
\text { Can connect via USB to } \\
\text { medical devices } \\
\text { (stethoscopes, otoscopes, } \\
\text { ultrasound, blood } \\
\text { pressure cuff, pulse } \\
\text { oximeter, etc.) }\end{array}$ & https://vsee.com/ \\
\hline WebEx & $\begin{array}{l}\text { Free, with options to } \\
\text { upgrade }\end{array}$ & Yes & $\begin{array}{l}\text { Microsoft Internet Explorer } \\
\text { Microsoft Edge } \\
\text { Google Chrome } \\
\text { Mozilla Firefox } \\
\text { Mac Safari } \\
\text { Chromium (Linux) } \\
\text { iOS } \\
\text { Android }\end{array}$ & Yes & $\begin{array}{l}\text { Powerful tool that is used } \\
\text { popularly for virtual } \\
\text { meetings as well }\end{array}$ & https://www.webex.com/ \\
\hline Zoom & $\begin{array}{l}\text { Basic: Free } \\
\text { Pro 14.99/mo/host } \\
\text { Business \& Enterprise } \\
\text { 19.99/mo/host }\end{array}$ & No & $\begin{array}{l}\text { Google Chrome } \\
\text { Mozilla Firefox } \\
\text { Microsoft Edge } \\
\text { MacOS X 10.9+ } \\
\text { Windows 7+ } \\
\text { iOS 8.0+ } \\
\text { iPadOS 13+ } \\
\text { Android 5.0x+ } \\
\text { Safari 5+ } \\
\text { Webkit }\end{array}$ & Yes & $\begin{array}{l}\text { Screen share } \\
\text { Collaboration } \\
\text { Password encryption }\end{array}$ & https://zoom.us/ \\
\hline
\end{tabular}




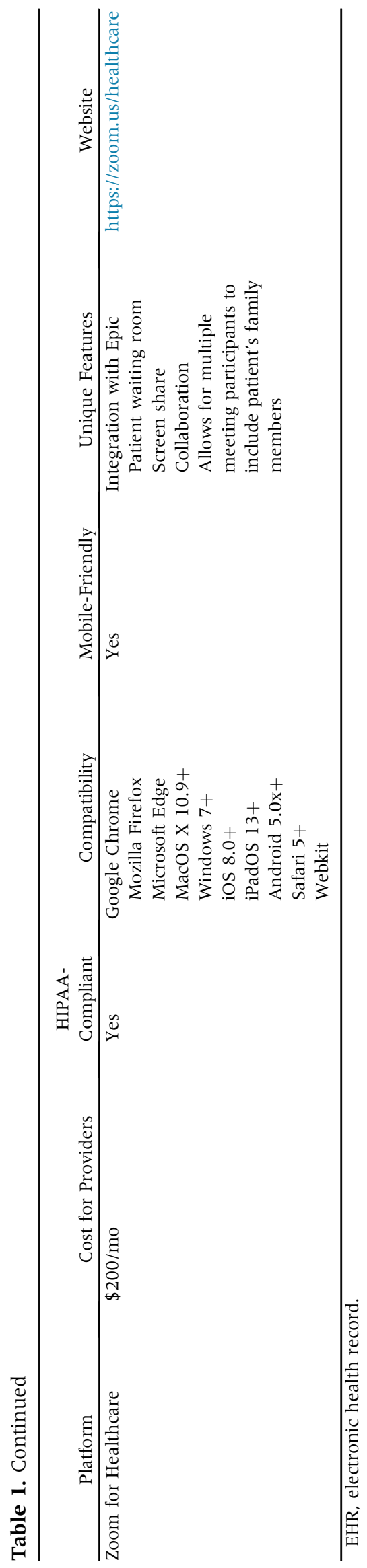

\section{Maintaining Resident Wellness}

\section{Sleep}

As evidenced by increased regulations of duty hours and vigilance for resident burnout, graduate medical education has made a particular focus on overall resident well-being in the past decade. ${ }^{26}$ Early reports from the current pandemic have already highlighted the importance of maintaining the clinicians' wellness in order to provide continued effective care. ${ }^{27}$ There are multiple factors that account for a residents' overall wellness. One factor that has been studied extensively in recent years is sleep deprivation. A study showed that physicians in their surgical residencies were $20 \%$ more likely to make errors during the day after they had been awake overnight when compared to those who had rested. ${ }^{28}$ Additionally, fewer than 7 hours of sleep per night have been shown to lead to adults' reporting higher rates of depression, asthma and heart attacks. ${ }^{29}$ A report from Wuhan, China, showed that fatigue was a significant risk factor for COVID-19 infection in orthopaedic surgeons. ${ }^{15}$ If well-rested residents are less likely to make medical errors and have lower rates of certain medical problems, it stands to reason that allotting more time for physicians-intraining to rest and sleep is better for both patients and trainees. By shifting the residents' rotations into teams that rotate out of the inpatient setting for 2 weeks and by incorporating night float, residents can maintain a healthful amount of sleep and rest. Additionally, conference times can be shifted from early in the morning to the afternoon so as to allow additional rest for residents who are not rounding on the inpatient service.

\section{Diet and exercise}

Another factor that is vital for residents' wellness is healthful eating habits. Diets high in antioxidants and omega-3 fatty acids have been shown to increase hippocampal synaptic plasticity and enhance cognitive function, whereas diets low in omega-3s have been associated with mental health disorders, such as depression, bipolar disorder and attention deficit disorder. $^{30}$ Exercise also has the ability to combat depressive properties while enhancing learning and memory. ${ }^{30,31}$ Residency programs and hospitals can support the mental and physical health of their residents by providing high-quality, healthful meal options, fitness facilities that have wellness instructors and allotted times to use these benefits.

\section{Self-care}

Finally, many residents neglect their own health problems in order to care for others. Several ways of improving health care access for time-pressed residents have been proposed. They include primary-care video 
Table 2. Popular Online Videoconferencing Platforms Useful for Didactic Education

\begin{tabular}{|c|c|c|c|c|c|c|c|c|c|c|}
\hline Name & Cost & $\begin{array}{l}\text { Attendant } \\
\text { Limit }\end{array}$ & Time Limit & Compatibility & Security & $\begin{array}{l}\text { HIPAA- } \\
\text { Compliant }\end{array}$ & Synchronous & $\begin{array}{c}\text { Screen } \\
\text { Share }\end{array}$ & Recording & $\begin{array}{c}\text { Dial-in } \\
\text { Compatible } \\
\end{array}$ \\
\hline Zoom Meeting & Free & 100 & 40 min $>3$ attendants & $\begin{array}{l}\text { Mac, Windows, Linux, } \\
\text { iOS, and Android }\end{array}$ & $\begin{array}{l}\text { 256-bit TLS } \\
\text { encryption }\end{array}$ & Yes & Yes & Yes & Yes & Yes \\
\hline Skype & Free & 50 & $\begin{array}{l}100 \mathrm{hr} / \mathrm{mo} ;<10 \mathrm{hr} / \text { day; } \\
\text { limit } 4 \mathrm{hr} / \text { individual call }\end{array}$ & $\begin{array}{l}\text { Mac, Windows, Linux, } \\
\text { iOS, and Android }\end{array}$ & AES & No & Yes & Yes & Yes & No \\
\hline Google Hangouts & Free & 25 & Unlimited & $\begin{array}{l}\text { Mac, Windows, Linux, } \\
\text { iOS, and Android }\end{array}$ & $\begin{array}{l}\text { Limited; No end-to- } \\
\text { end encryption }\end{array}$ & No & Yes & Yes & Yes & No \\
\hline $\begin{array}{l}\text { Cisco Webex } \\
\text { Meetings }\end{array}$ & Free & 100 & Unlimited & $\begin{array}{l}\text { Mac, Windows, Linux, } \\
\text { iOS, and Android }\end{array}$ & $\begin{array}{l}\text { TLS } 1.2 \text { and AES } \\
\text { 256-bit }\end{array}$ & No & Yes & Yes & Yes & Yes \\
\hline $\begin{array}{l}\text { Google Hangouts } \\
\text { Meet }\end{array}$ & $\$ 6 / \mathrm{mo}$ & $\begin{array}{l}250 \text { participants } \\
100,000 \text { live } \\
\text { stream viewers }\end{array}$ & Unlimited & $\begin{array}{l}\text { Mac, Windows, Linux, } \\
\text { iOS, and Android }\end{array}$ & $\begin{array}{l}\text { Automation } \\
\text { meeting ID, } \\
\text { restrict } \\
\text { external } \\
\text { participants }\end{array}$ & Yes & Yes & Yes & Yes & Yes \\
\hline $\begin{array}{l}\text { Zoom Meeting } \\
\text { Pro }\end{array}$ & $\$ 14.9 / \mathrm{mo}$ & 100 & $24 \mathrm{hr}$ & $\begin{array}{l}\text { Mac, Windows, Linux, } \\
\text { iOS, and Android }\end{array}$ & $\begin{array}{l}\text { 256-bit TLS } \\
\text { encryption }\end{array}$ & Yes & Yes & Yes & Yes & Yes \\
\hline $\begin{array}{l}\text { Zoom Meeting } \\
\text { Business }\end{array}$ & $\$ 19.99 / \mathrm{mo}$ & 300 & $24 \mathrm{hr}$ & $\begin{array}{l}\text { Mac, Windows, Linux, } \\
\text { iOS, and Android }\end{array}$ & $\begin{array}{l}\text { 256-bit TLS } \\
\text { encryption }\end{array}$ & Yes & Yes & Yes & Yes & Yes \\
\hline $\begin{array}{l}\text { GoToMeeting } \\
\text { Professional }\end{array}$ & $\$ 12 / \mathrm{mo}$ & 150 & Unlimited & $\begin{array}{l}\text { Mac, Windows, Linux, } \\
\text { iOS, and Android }\end{array}$ & $\begin{array}{l}\text { AES-256 and SSL } \\
\text { encryption }\end{array}$ & Yes & Yes & Yes & Yes & Yes \\
\hline $\begin{array}{l}\text { GoToMeeting } \\
\text { Professional } \\
\text { Business }\end{array}$ & $\$ 16 / \mathrm{mo}$ & 250 & Unlimited & $\begin{array}{l}\text { Mac, Windows, Linux, } \\
\text { iOS, and Android }\end{array}$ & $\begin{array}{l}\text { AES-256 and SSL } \\
\text { encryption }\end{array}$ & Yes & Yes & Yes & Yes & Yes \\
\hline
\end{tabular}


Table 3. Well-Being Chart Covering the Mental, Physical and Social Aspects Along With Barriers and Protective Factors

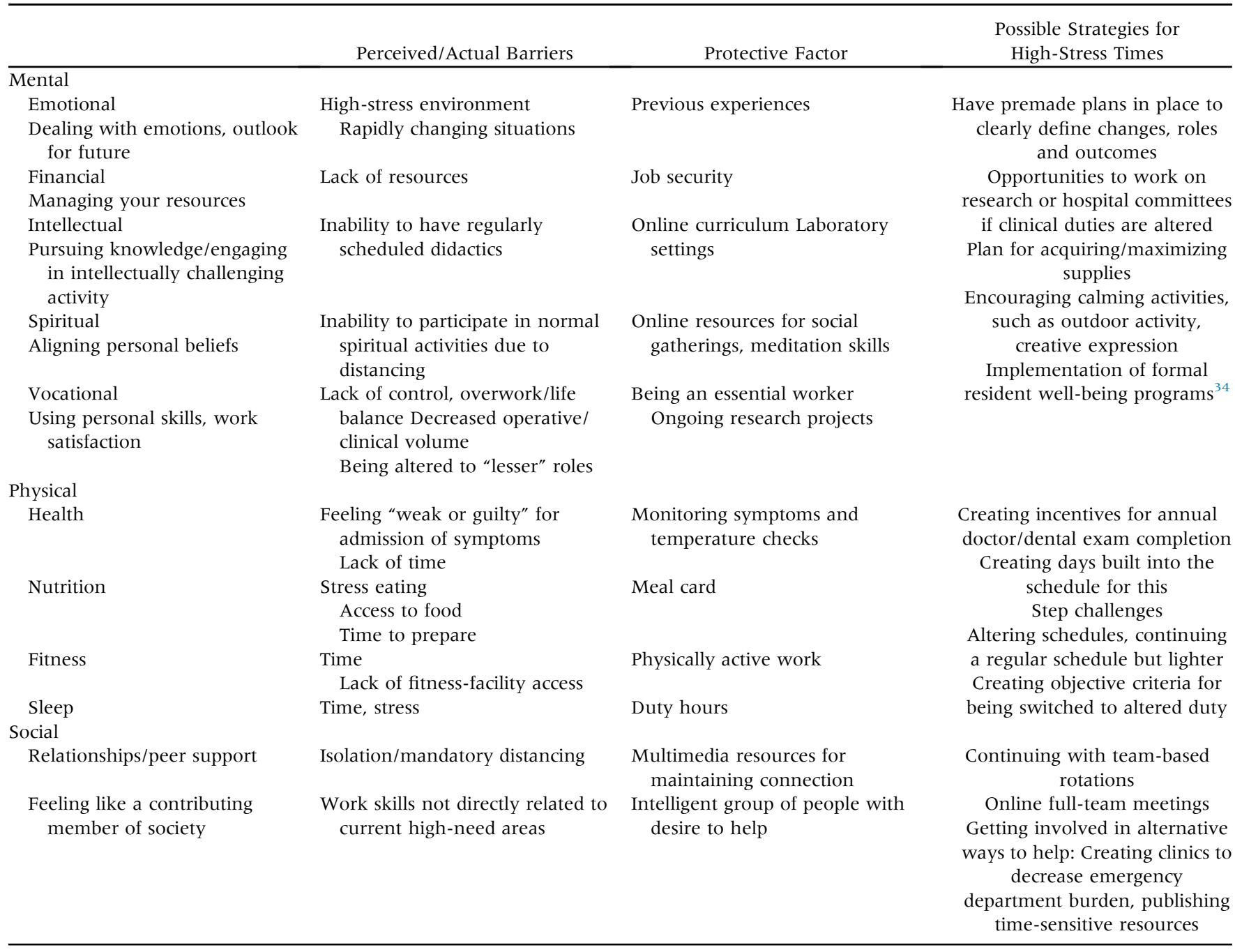

visits for trainees as well as concierge scheduling services, which include rapid-response telephone services with flexible scheduling for visits. These methods have been shown to decrease perceived barriers and delays to health care among residents. ${ }^{32}$

According to the Green Cross Academy of Traumatologists, standards of self-care are based on 2 rules: "First, do no harm to yourself in the line of duty when helping/treating others. Second, attend to your physical, social, emotional, and spiritual needs as a way of ensuring high-quality services to those who look to you for support as a human being." ${ }^{33}$ Achieving true wellness involves a multifaceted approach, and it is the responsibility of both the residents and their programs to keep trainees healthy and functioning at high levels. This serves to benefit residents, their programs and their patients. During this tumultuous time, focusing on resident wellness may be beneficial in preventing COVID-19 infection and symptoms in trainees. Table 3 includes facets of wellness that incorporate those listed in the Green Cross Academy of Traumatologists guidelines, with barriers and some strategies to consider in addressing these issues. ${ }^{33}$

\section{Medical Student, Resident, and Fellow Current Issues and Future Directions}

\section{Medical Students}

Over the past several years, medical schools across the country have been increasingly changing their curricula to being online and allowing students to learn wherever and whenever they prefer. The COVID-19 pandemic has caused many more medical schools to transition rapidly to a similar style of teaching in order to keep their students safe. ${ }^{35}$ Our institution has implemented many changes like these so as to keep students physically distanced and to avoid the spread of COVID-19.

At our institution, preclinical medical students switched entirely to online lectures during the COVID19 pandemic. This allowed them to continue their medical education and move toward their clinical years while maintaining physical distance from their 
classmates and others. Students were able to learn from the safety of their own homes yet not fall behind during this critical time in their education. Clinical students were able to complete online modules to simulate their rotations. Although this is not the same as caring for actual patients in the hospital, it does allow the students to continue to learn how to care for patients while avoiding unnecessary exposure and avoid depleting the hospital's PPE. Additionally, fourth-year medical students were graduated early to allow them to start as interns at their respective residency programs if needed in areas that were understaffed during the pandemic.

Going forward, several changes will be instituted to avoid further spread of COVID-19 with regard to medical students, as well as to protect them from exposure. First, as recommended by The Coalition for Physician Accountability's Work Group, all interviews for medical school will be virtual. ${ }^{36}$ This will prevent students from all over the country from gathering together in large groups in small interview rooms, thus risking spread of COVID-19 across states lines when they return home. Second, away rotations for medical students are strongly discouraged unless the students' home programs do not have the specialties they are hoping to go into or that are required for their graduation. ${ }^{36}$ At our institution, we will be expanding the amount of time that medical students can spend on subspecialty rotations within orthopedics because they will not be completing away rotations. This will include rotations such as sports medicine, hand, orthopedic research, etc., for up to 4 -week blocks. Finally, most orthopaedic programs will not be performing in-person interviews, so we have increased our social media presence and created videos of our institution for interviewees. Interviewees will not be able to visit any potential orthopaedic programs in person, so it is important that all programs provide a robust amount of media so the interviewees can get to know the program virtually.

\section{Residents}

The strategies outlined in this article have proven to be successful at our institution during the COVID crisis. Other residencies have documented their experiences, though limited follow-up has been described. ${ }^{14,17,22,23}$ In the event of a second wave of the virus, many of these same approaches will be implemented again through a coordinated effort by the faculty and residents to ensure the safety of all members of the orthopaedic department while continuing to deliver excellent patient care and maintaining proper orthopaedic education.

After the publication of these seminal articles, a few other considerations have manifested as residencies approached the end of the academic year. Fifth-year residents typically dedicate the latter half of the year to prepare for board examinations. This would usually entail attending board-review courses. A schedule was created so that all the national orthopaedic meetings are available to residents. Additional measures, such as protecting time for these senior residents to focus on studying or to attend virtual courses, should be considered. Applying for the board examination should also be planned as soon as possible because special accommodations may need to be made due to socialdistancing limitations at testing centers. ${ }^{37}$

\section{Resident Case Volumes}

It should be noted that in addition to attending to the clinical needs of patients, to graduate, orthopaedic residents-in-training are required to experience a certain number of surgical cases in various areas. Among the core case requirements, minimums are required for knee arthroscopy, shoulder arthroscopy, anterior cruciate ligament reconstruction, total hip arthroplasty, total knee arthroplasty, spine decompression/posterior spine fusion, foot and ankle fusion, carpal tunnel release, and oncologic procedures. Many of these cases were not performed during the pandemic, so that may affect the numbers of cases that graduating residents who were training during the pandemic will have experienced.

We have found that with extensive planning and stockpiling of cases, residents will be able to graduate with adequate surgical training. Some programs have ramped-up elective surgery, and they have added surgical days on weekends to catch up. When surgical volumes are down, some programs have supplemented surgical training with simulation-based training or virtual training. ${ }^{38}$ Because of the nature of surgical rotations, it is likely that each resident will be deficient in a single area (arthroplasty). This needs to be taken into account when planning future rotations; there may be a resident who missed out on joint arthroplasty and will need a future arthroplasty rotation to compensate. In our program, residents who missed sports-medicine cases and arthroplasty cases were given compensatory rotations the following year. Finally, when orthopaedic programs complete their annual ACGME report, they should clearly communicate resident-case deficiencies as they relate to the pandemic.

\section{Fellows}

In contrast to the 5 years of residency training, orthopaedic fellows must complete their focused subspecialty training in 1 year. Interruption of this highly concentrated year can have drastic implications for the fellow in training. Fellows this year have been met with unexpected challenges, such as decreased surgical volumes due to canceled elective cases and clinic encounters, disruptions of specialty meetings and didactics. Dowdell et al. described their spine-surgery fellowship experience in 
New York City during the height of COVID-19 and noted that the ideal number of spine cases to be performed during this year was 250 and, luckily, this metric was met prior to mid-March of $2020 .{ }^{39}$ However, such luck may not hold true across all fellowships. In light of these conditions, the ACGME has released statements recognizing these shortcomings and recommends ultimately placing the onus on the program director to determine whether a fellow is ready to graduate. ${ }^{40}$

An additional facet that must be considered is the role of international candidates who fill these fellowship positions in the United States. Not only will they be subject to the limitations of our country and the quarantine times that must be imposed upon their arrival in the United States, but they may also be confronted by visa issues as well as the travel restrictions of their own countries. This could, in some cases, prevent them from completing the year altogether. At our institution, a visiting international fellow arrived just prior to the declaration of COVID-19 as a pandemic. The fellow was quarantined for 2 weeks and then returned home shortly thereafter. It is unclear how the role of the international fellow will change this year, but it will almost certainly be subject to many restrictions.

The fellow in training will also be met with challenges in employment. Traditional in-person interviews with practices may be substituted by virtual meetings in light of travel restrictions and coronavirus precautions. Employers may also be in hiring freezes due to the allocation of resources to other priorities, such as maintaining intensive care units and PPE, which will make job vacancies that much harder to find. Indeed, this is a time of uncertainty, with a unique set of obstacles unseen by previous fellows.

\section{Return to Elective Surgery and Increasing Case Volumes}

During the early phase of the COVID-19 pandemic, the Surgeon General recommended the discontinuance of "elective surgeries." ${ }^{41}$ This had many sequelae, including an exponentially decreased surgical volume in orthopaedic surgery programs and economic impacts on surgery centers and hospital systems. As clinical volume decreased significantly, a correlative decrease in personnel hours occurred in many groups. ${ }^{42}$ During the height of the pandemic, many orthopaedic programs decided to perform only emergent, urgent or expedited surgery (surgery that should be done within 2 weeks). At our institution, the decisions about which surgeries should be done when resources were scarce were made at the local level by a committee of surgeons and anesthesiologists, based on the resources that were available.

When orthopaedic programs are seeing patients primarily via telemedicine, surgeries can still be scheduled. It is important that surgeons have clear communication with patients that the surgery will not be performed until state and local leaders have recommended a return to elective surgery. During this low surgicalvolume time, cases can be stockpiled and categorized according to their priority on the basis of various recommendations. ${ }^{14,43,44}$ By continuing to evaluate patients for surgery, maintaining an organized list of surgical patients and communicating clearly with patients, surgeons will be able to increase their surgical volumes rapidly.

\section{Prioritizing Cases During Surgical Volume Increases}

As hospitalizations due to COVID-19 decrease, and hospital resources become stable, orthopaedic training programs should strategically plan which nonemergent cases to prioritize. In the event that there is a secondwave phenomena, as occurred with SARS in Canada, it is prudent to prioritize short-term, delayed surgeries. ${ }^{45}$ A stratified urgency of orthopaedic surgeries has been described on the basis of how long it is safe to delay various types of orthopaedic surgeries. ${ }^{14}$ As we ramped-up nonemergency surgeries again, we prioritized the surgeries that should not be delayed more than 3 months, such as acute rotator cuff repairs in younger patients, anterior cruciate ligament reconstruction and multiligamentous knee reconstructions. Once the backlog of these short-term delayed surgeries had been surgically treated, then all surgical priority surgeries were resumed.

\section{Total Joint Arthroplasty}

Additionally, many hospitals decreased their staffing for financial efficiency; a rebound in staffing should occur. Prior to ramping-up elective surgeries, our department met with hospital leadership, nursing leadership and anesthesia leadership to ensure that proper personnel resources would be available for the resurgence of elective cases. Total joint arthroplasty should be resumed when there is resource availability with respect to hospital beds, intensive care unit beds and blood transfusion products. ${ }^{46}$ When these resources are appropriate, and a committee involving anesthesia teams, intensive care unit management, hospital-bed management, and surgeons determines it is appropriate, return to total joint arthroplasty can resume.

\section{Preoperative COVID-19 Testing}

As orthopaedic surgeries ramp up again, it is important to maintain a safe environment for residents and patients. Recommendations have been made by numerous authors and organizations about how to resume surgery safely. ${ }^{14,43}$ Some key points are that all patients receiving nonurgent orthopaedic surgery must have a SARS-CoV-2 reverse transcription polymerase chain reaction test performed prior to surgery. ${ }^{43}$ When a patient tests positive for COVID-19, the nonemergent 
orthopaedic surgery should be delayed. Also, when an emergent or urgent surgery in a patient with COVID-19 is performed at our institution, only 1 resident is allowed in the surgery, and no medical students are allowed.

\section{Conclusion}

The COVID-19 pandemic has presented a multitude of challenges to health care professionals, not only in handling the care of patients but also in maintaining traditional graduate medical education. Indeed, these are unprecedented times; however, we present adaptations to the structure of the complement of residents, changes to residents' work environments and modifications to education that will enable residency programs to function during this crisis. Residents should follow and understand guidelines for PPE, have team structures that employ physical distancing, maintain clinical care via telemedicine, maintain education via teleconferencing, and focus on well-being to enable the continued success and functionality of the residency. With flexibility and strategic planning, training programs can adapt to be ready for second-wave events or future pandemics.

\section{Acknowledgements}

The authors would like to acknowledge that Anna Hoefler assisted with preparation of the tables and manuscript.

\section{References}

1. American College of Graduate Medical Education. Three stages of GME during the COVID-19 pandemic. https:// acgme.org/COVID-19/-Archived-Three-Stages-of-GMEDuring-the-COVID-19-Pandemic. Accessed June 17, 2020.

2. Tyrrell DA, Bynoe ML. Cultivation of viruses from a high proportion of patients with colds. Lancet 1966;1:76-77.

3. Almeida JD, Tyrrell DA. The morphology of three previously uncharacterized human respiratory viruses that grow in organ culture. J Gen Virol 1967;1:175-178.

4. World Health Organization. Middle East respiratory syndrome coronavirus (MERS-CoV)-Republic of Korea May 24, 2015.

5. Leibowitz JL. Coronaviruses: Molecular and cellular biology. Emerg Infect Dis 2008;14:693-694.

6. Li W, Wong SK, Li F, et al. Animal origins of the severe acute respiratory syndrome coronavirus: Insight from ACE2-S-protein interactions. J Virol 2006;80:4211-4219.

7. Cucinotta D, Vanelli M. WHO declares COVID-19 a pandemic. Acta Biomed 2020;91:157-160.

8. BBC News Visual and Data Journalism Team. Coronavirus: A visual guide to the pandemic. https://www.bbc. com/news/world-51235105. Accessed June 17, 2020.

9. Centers for Disease Control and Prevention. Coronavirus Disease 2019 (COVID-19): Social distancing, quarantine, and isolation April 4, 2020.
10. Prem K, Liu Y, Russell TW, et al. The effect of control strategies to reduce social mixing on outcomes of the COVID-19 epidemic in Wuhan, China: A modelling study. Lancet Public Heal 2020;5:e261-e270.

1 1. Backer JA, Klinkenberg D, Wallinga J. Incubation period of 2019 novel coronavirus (2019-nCoV) infections among travellers from Wuhan, China, 20-28 January 2020. Euro Surveill 2020;25:20-28.

12. Sabharwal S, Ficke J, Laporte D. How we do it: Modified residency programming and adoption of remote didactic curriculum during the COVID-19 Pandemic. J Surg Educat 2020;77:1033-1036.

13. Stinner DJ, Lebrun C, Hsu JR, et al. The Orthopaedic Trauma Service and COVID-19: Practice considerations to optimize outcomes and limit exposure. J Orthop Trauma 2020;34:333-340.

14. Massey PA, McClary K, Zhang AS, et al. Orthopaedic surgical selection and inpatient paradigms during the coronavirus (COVID-19) pandemic. J Am Acad Orthop Surg 2020;28:436-450.

15. Guo X, Wang J, Hu D, et al. The Orthopaedic Forum Survey of COVID-19 disease among orthopaedic surgeons in Wuhan, People's Republic of China. J Bone Joint Surg 2020;102:847-854.

16. Chang Liang Z, Wang W, Murphy D, Po Hui JH. Novel coronavirus and orthopaedic surgery: Early experiences from Singapore. J Bone Joint Surg 2020;102:745-749.

17. Schwartz A, Wilson J, Boden S, et al. Manging resident workforce and education during the COVID-19 pandemic. J Bone Joint Surg Open Access 2020;5:e0045.

18. Kampf G, Todt D, Pfaender S, Steinmann E. Persistence of coronaviruses on inanimate surfaces and their inactivation with biocidal agents. J Hosp Infect 2020;104:246-251.

19. Trauma ACoSCo. Maintaining trauma center access \& care during the COVID-19 pandemic: Guidance document for trauma medical directors. https://www.facs.org/ quality-programs/trauma/maintaining-access. Accessed June 17, 2020.

20. Centers for Medicare and Medicaid. Medicare coverage and payment of virtual services. Medicare telemedicine health care provider fact sheet 2020.

21. Guy D, Bosco J, Savoie F. American Academy of Orthopaedic Surgeons. AAOS guidelines for elective surgery during the COVID-19 pandemic 2020.

22. Kogan M, Klein SE, Hannon CP, Nolte MT. Orthopaedic education during the COVID-19 pandemic. J Am Acad Orthop Surg 2020;28:e456-e464.

23. Sarpong NO, Forrester LA, Levine WN. What's important: Redeployment of the orthopaedic surgeon during the COVID-19 pandemic: Perspectives from the trenches. J Bone Joint Surg 2020;102:1019-1021.

24. Davis L. Surgeons-in-training learn important skills to back up key allies during the coronavirus pandemic. Nurses. https://news.usc.edu/167632/surgical-residentsnurses-critical-care-covid-19/. Published April 1, 2020. Accessed June 17, 2020.

25. Sengupta S. With virus surge, dermatologists and orthopedists are drafted for the E.R. $N Y$ Times. https://www.nytimes.com/2020/04/03/nyregion/new-yorkcoronavirus-doctors.html. Published April 3, 2020. Accessed June 17, 2020. 
26. Busireddy KR, Miller JA, Ellison K, et al. Efficacy of interventions to reduce resident physician burnout: A systematic review. J Grad Med Educ 2017;9:294-301.

27. Bansal P, Bingemann TA, Greenhawt M, et al. Clinician wellness during the COVID-19 pandemic: Extraordinary times and unusual challenges for the allergist/immunologist. J Allerg Clin Immunol Pract 2020;8:1781-1790.e3.

28. Taffinder NJ, McManus IC, Gul Y, et al. Effect of sleep deprivation on surgeons' dexterity on laparoscopy simulator. Lancet 1998;352:1191.

29. Centers for Disease Control and Prevention. How does sleep affect your heart health? https://www.cdc.gov/ features/sleep-heart-health/index.html.

Published December 3, 2018. Accessed June 17, 2020.

30. Gomez-Pinilla F. The influences of diet and exercise on mental health through hormesis. Ageing Res Rev 2008;7: 49-62.

31. Rethorst CD, Wipfli BM, Landers DM. The antidepressive effects of exercise: A meta-analysis of randomized trials. Sports Med 2009;39:491-511.

32. Tan C, Kuhn C, Anderson J, et al. Improving well-being among trainees: A partnership to reduce barriers to primary care services. J Grad Med Educ 2020;12:203-207.

33. Green Cross Academy of Traumatology. Standards of Care 2020.

34. Riall TS, Teiman J, Chang M, et al. Maintaining the fire but avoiding burnout: Implementation and evaluation of a resident well-being program. J Am Coll Surg 2018;226:369-379.

35. Rose S. Medical student education in the time of COVID19. J Am Med Assoc 2020;323:2131-2132.

36. The Coalition for Physician Accountability's Work Group on Medical Students in the Class of 2021. Moving across institutions for postgraduate training 2020. AAMC. Final report and recommendations for medical education institutions of LCME-accredited, U.S. osteopathic, and nonU.S. medical school applicants. https://www.aamc.org/ system/files/2020-05/covid19_Final_Recommendations_ 05112020 .pdf. Accessed June 17, 2020.
37. Wright RW, Armstrong AD, Azar FM, et al. The American Board of Orthopaedic Surgery Response to COVID-19. J Am Acad Orthop Surg 2020;28:e465-e468.

38. Plancher K, Shanmugam JP, Petterson SC. The changing face of orthopedic education: Searching for the new reality After COVID-19. Arthrosc, Sports Med Rehab 2020;2: e295-e298.

39. Dowdell JE, Louie PK, Virk S, et al. Spine fellowship training reorganizing during a pandemic: Perspectives from a tertiary orthopedic specialty center in the epicenter of outbreak. Spine J 2020;20:1381-1385.

40. Nasca T. ACGME response to the coronavirus (COVID19) 2020.

41. Oliver E. US Surgeon General: Stop elective procedures. Becker's ASC Review. https://www.beckersasc.com/ leadership/us-surgeon-general-stop-elective-procedures. html. Published March 16, 2020. Accessed June 17, 2020.

42. Vaccaro AR, Getz CL, Cohen BE, et al. Practice management during the COVID-19 pandemic. J Am Acad Orthop Surg 2020;28:464-470.

43. Parvizi J, Gehrke T, Krueger CA, et al. Resuming elective orthopaedic surgery during the COVID-19 pandemic: Guidelines developed by the International Consensus Group (ICM). J Bone Joint Surg Am 2020;102: 1205-1212.

44. Sarac N, Sarac B, Schoenbrunner A, et al. A review of state guidelines for elective orthopaedic procedures during the COVID-19 outbreak. J Bone Joint Surg: The Orthopaedic Forum 2020;102:942-945.

45. Ofner-Agostini M, Wallington T, Henry B, et al. Investigation of the second wave (phase 2) of severe acute respiratory syndrome (SARS) in Toronto, Canada. What happened? Can Commun Dis Rep 2008;34: $1-11$.

46. O'Connor CM, Anoushiravani AA, DiCaprio MR, et al. Economic recovery after the COVID-19 pandemic: Resuming elective orthopedic surgery and total joint arthroplasty. J Arthroplasty 2020;35:S32-S36. 